\section{Health services in Sweden}

Sweden's health is good: infant and perinatal mortality are low and life expectancy long, and she is at the top of the league on several indices of good health and generous provision. The health service, run by the county councils, is comprehensive and paid for through taxation and compulsory health insurance. Most doctors work for the counties and most are specialists working in hospitals. In common with Britain and other Western nations, Sweden has been trying to switch the emphasis from the expensive acute sector towards primary care and meeting the needs of increasing numbers of elderly people. The major brake to progress has been the small proportion of general practitioners. Despite centralised control over medical posts and despite the fact that Sweden has more doctors per head than England, posts in rural Sweden and in unpopular specialties (those with a community orientation) have proved hard to fill.

One reason why the pattern of health care has been so slow to change lies in the traditional autonomy of the county councils and the fact that primary and psychiatric services, which the counties took over from the State in the 1960s, had long been underfunded. The 23 counties and three municipalities with responsibility for health (Gotland, Göteburg, and Malmö) have populations ranging from 54000 to $1.5 \mathrm{~m}$; providing them with health and related services is the counties' major function and takes about $80 \%$ of their expenditure.

\section{Organisation}

Outpatient care is organised in districts of 10000 to 50000 people, served by health centres and nursing homes for patients needing long-term care. The health centres are staffed by general practitioners (district medical officers), nurses, and paramedical staff such as physiotherapists and sometimes also specialists from hospital departments. Despite the trend towards primary care half of all outpatient consultations are still with specialists in hospital outpatient clinics. Hospitals range from local general hospitals, with 300 or so general medical and surgical beds, to county hospitals with a range of specialties, and to the seven regional hospitals, six of them teaching hospitals, which have 1200-2300 beds and provide the superspecialties. The only hospitals outside this system are the two State institutes-the Karolinska in Stockholm and the Academiska in Uppsala.

Although national medical insurance has been compulsory since 1955, with employers and the self-employed bearing the costs and patients themselves paying a fee for an outpatient visit or day spent in hospital, social insurance payments to county councils amount to only $7 \%$ of the counties' income-and payments from patients to $3 \%$. Most of the money $(67 \%$ ) comes from county council taxes and the rest from State grants. The latter are mainly for mental health, which the counties took over from the State in 1967, and for the clinical training of doctors. The rest are tax equalisation grants, paid to iron out the greatest disparities in health expenditure between the richest and poorest counties: in 1977 expenditure on hospital care ranged from $3299 \mathrm{kr}(£ 366)$ per head in Uppsala to $2219 \mathrm{kr}(£ 246)$ in the neighbouring county of Västmanland (compared with $£ 81$ in England).

A change in the social insurance system in 1970 , designed to encourage patients to use outpatient services rather than expensive inpatient care, also turned most doctors into salaried employees of the counties. Before 1970 patients paid doctors part of their fees direct and charges were calculated on an item-ofservice basis, thus ensuring different salaries in different specialties. Since 1970 patients have paid a standard fee (now about $£ 2 \cdot 20$ ) at each visit to a district medical officer or hospital outpatient clinic (this covers any investigations and referral). The social insurance office pays the remainder of the fee (about $f_{10}$ ) to the county and the doctor receives a salary. Inpatients contribute about $£ 3.30$ a day, which is deducted from their sick pay and paid to the county. Doctors' salaries are about $£ 1700-£ 1900$ a month for specialists and district medical officers, $£ 1100$ 1200 for junior doctors in specialist training, and about $£ 880$ for those who have just qualified.

Although publicly employed doctors may do private practice outside their hospital and in their own time, only about 800 of Sweden's 17000 doctors are in full time (mainly outpatient) private practice. They tend to be an aging group, they work mainly in the cities, and most work within the social insurance system. Thus their patients still pay only a flat-rate fee, albeit a slightly higher one, and the doctor is reimbursed the rest according to a tariff. Patients who consult private practitioners outside the insurance scheme have to bear the entire cost.

\section{National influences}

The National Board for Health and Welfare has a supervisory and standard-setting role. It is responsible for supervising both the health care provided by the counties and the social services provided by the communes (secondtier authorities). Its powers of actual control lie largely in approving specialist and medical training posts throughout Sweden. Until recently it also approved counties' capital programmes; now their only limit is an investment ceiling set by the Minister of Health.

Further decentralisation of some of the board's more detailed responsibilities is under way. It now concentrates on standard setting and monitoring-for example, in analysing the counties' long-term plans and progress towards their targets and in setting up models for the organisation of the medical and social care of groups such as the elderly, diabetics, and patients with hypertension.

The board also runs two committees responsible for aspects of the work of doctors, though their predominantly lay memberships are appointed by the Minister of Health.
The Medical Responsibility Board licenses doctors to practise once they have graduated and served their 21 months' general service training. Since Sweden has no-fault compensation for medical injuries few claims of negligence go direct to the courts. Instead patients may complain to the responsibility board about the conduct of doctors, nurses, and paramedical staff. After investigation the board may withdraw a doctor's licence to practise, issue a warning, or refer a case to the courts, which may fine him or award damages.

Postgraduate Medical Education CommitteePostgraduate training falls into two partsgeneral service, when the medical graduate has to take a 21-month job that will provide him with experience in medicine, surgery, psychiatry, and primary care before he is licensed to practise; and specialist training. General service posts are shared among the counties as part of the national board's attempts to distribute doctors fairly between different parts of the country. Despite these efforts, graduates still manage to find shortterm posts in the university towns, while general service posts in the north remain unfilled. The same problem of maldistribution dogs specialist training. The length of training in each specialty is laid down by legislation and, with the advice of specialty boards, the education committee works out the components of each course. Training for each specialty is standard and each post provides the doctor with all the components he needs if he has a special interest which is not covered in the standard post he may be able to get a short-term post in that area when he has finished his training posts, but it is largely a matter of luck. Changing specialty in midcourse needs the committee's permission and usually means that the doctor has to start from scratch and apply for another post. Trainee specialists must also attend six courses in subjects relevant to their specialty run by the committee and pass an exam at the end of each before they will be accredited as specialists.

Although the system is geared to distributing posts around Sweden and providing the right numbers in each specialty, rural posts tend to lie empty and too few doctors are training to become general practitioners, geriatricians, physicians in long-term care, and psychiatrists.

\section{Planning and rationalising}

At national level two other bodies have an important influence on health policy and

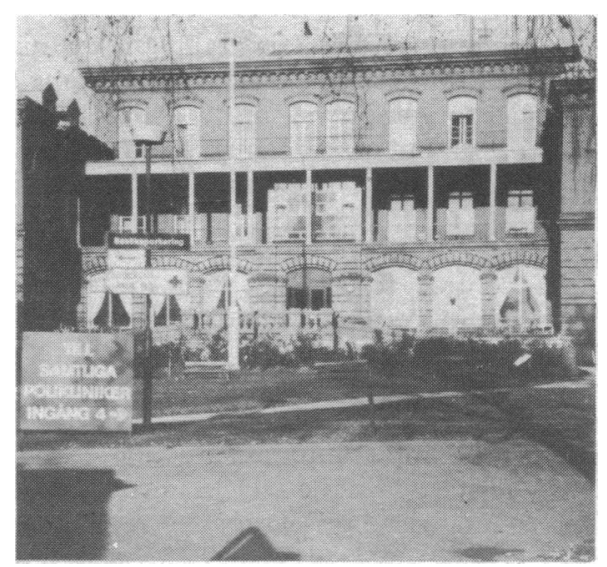

The famous Serafimer Hospital, in the centre of Stockholm, closed earlier this year; its work is now done by large modern hospitals on the outskirts. 
organisation: the Federation of County Councils and SPRI-the Swedish Planning and Rationalisation Institute of the Health Service. The federation acts as a political lobby for the county councils, negotiates with their staff over pay and plays an educational and advisory role. In some of its organisational research it overlaps with both the national board and SPRI, which was set up jointly by the federation and national board. As its name suggests, SPRI's aim is to improve the organisation of health services-with an increasingly sharp eye on cost effectiveness. It also tests and evaluates medical equipment and does development work for some of the smaller counties, which do not have large planning staffs.

\section{Priorities}

During the 1960s the health service expanded and costs rose. In the 70 s costs continued to rise but the rate of expansion fell sharply. Working hours fell; the wages of the low paid, who predominate in the health service, rose faster than average; and rising expectations and increasing numbers of elderly people created greater burdens. At the same time the working population was falling and with it its capacity (and willingness) to support other sectors of the population through high taxes. These trends account partly for the Swedes' current emphasis on switching resources towards primary care and long-term care for the elderly.

The slow switch in emphasis has taken place against a background of one of the highest ratios of hospital beds per population in the world (14.3/1000, of which 5 are acute compared with 8.5 in Great Britain ( 3 acute)) and small numbers of general practitioners (only $10 \%$ of Swedish doctors). Although Sweden has had district medical officers providing individual populations with medical care since the seventeenth century this pattern predominated in rural areas, where specialists and hospitals were few or inaccessible. Swedes have long been used to taking their problems straight to a specialist, and changing the habits of patients and doctors is proving a slow task. The counties aim to have over half outpatient visits made to district health centres by 1985 , but in the late 70 s only $25 \%$ of visits were made there (private practitioners, two-thirds of whom are specialists, accounted for another $25 \%$ ).

Health centres are designed to serve the primary health care needs of a specific population. Patients do not register with a GP and do not need his referral to see a specialist. The original idea of building health centres for 15 or so doctors has now been modified in favour of 5- to 6-doctor centres, partly to aid accessibility. In an attempt to provide some continuity of care (which is lacking at hospital outpatient departments), some health centres have organised themselves so that one doctor and nurse serve each small sub-area and a patient will usually see the same people at each visit. Health centres are often associated with an old people's home, run by the commune, and a long-term nursing home, all serving the same community. But expanding primary care and community services has not been without its problems. The old people's homes and social services are run by a different authority from the health service, and there are problems of co-ordination and communication. The lack of doctors trained in
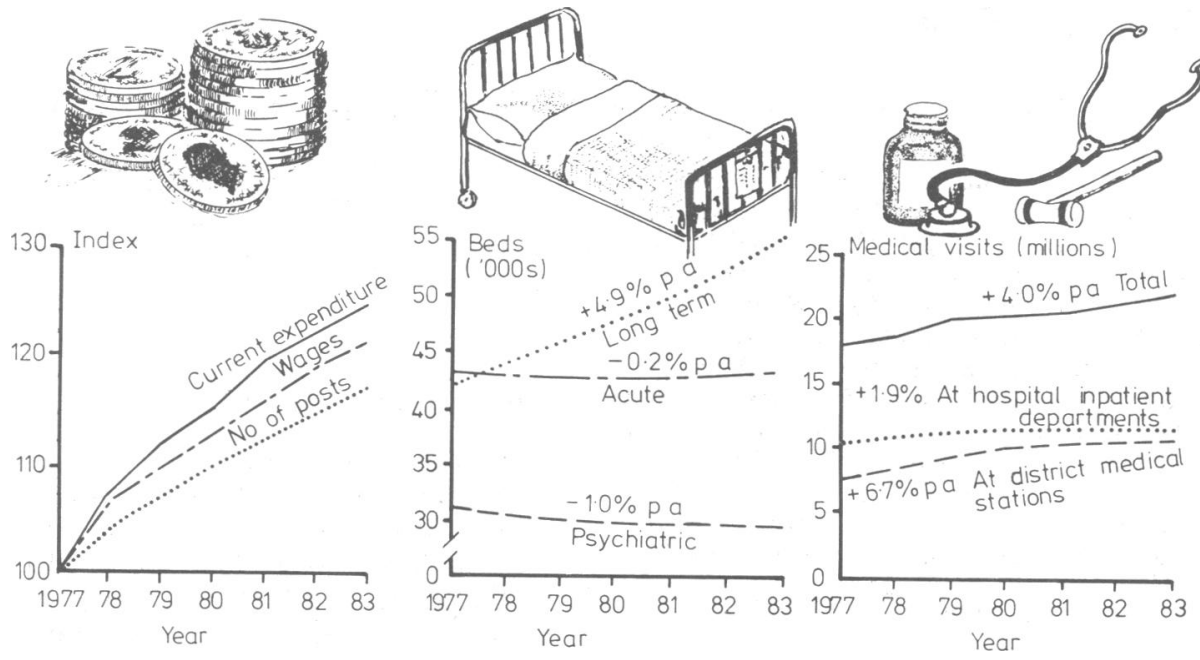

Trends in Sweden's health services: statistics from the counties' plans for 1977-83.

general practice has meant that some centres are undermanned. Even at fully staffed centres the tendency of Swedish doctors to spend 20 minutes on each consultation means that waiting times for non-urgent appointments may be $2-3$ weeks. Though this compares well with waiting times at hospital specialist clinics it is not surprising that patients bypass the queue and take themselves off to the casualty department. This tendency also weakens the epidemiological base of general practice. When a health centre expects over some years to see all the inhabitants of its community it can base its work on a sound knowledge of the community's health -an approach that seems to work well outside the major cities.

\section{Too many doctors?}

When the social insurance reforms of 1970 brought such a radical change to doctor's contracts, the Swedish Medical Association fought hard to limit hours of work in exchange. Now a doctor's basic salary is for a 40-hour week, and, although many doctors contract to work longer, overtime is paid. Nevertheless, tax on overtime is high and increasingly doctors are choosing to take time off rather than work longer hours for extra pay. This has compounded Sweden's traditional problem of having too few doctors and has also been one reason why the national board's control over specialist and training posts has failed to move doctors to unpopular areas and specialties. Because of the limited working hours county councils have to employ other doctors to do the job of the proper holder of a post when he is off duty. There are thus plenty of permanent locum posts available in the cities and in popular specialties which doctors can take rather than move to vacant posts.

The question of working hours also bedevils the issue of how many doctors Sweden needs and whether it is producing too many (it already has $19 / 10000$ compared with England's 14). In an effort to increase numbers (the planned increase in publicly employed doctors in $1973-9$ was $46 \%$ ) the six Swedish medical schools now take just over 1000 students a year. But recent legislation has also reduced the average working life of a doctor. Now only a minority of students come straight from school; measures to enable older Swedes to have a full-time university education have increased the average age of a medical student from 22 to 28, and the Swedish press has highlighted cases of people starting medical courses who will be beyond retirement age by the time they finish.

It is too early to assess the long-term effects of the scheme, but some Swedish doctors think that it might help to fill the empty posts in general practice and long-term care, since the older students tend to be more interested in these specialties. Meanwhile the academics fear for recruitment to teaching and research.

\section{Academic medicine}

There has been a strong tradition that young Swedish doctors should spend time engaged in both preclinical and clinical research (non-career research posts funded by Sweden's Medical Research Council last six years) before aiming for a good post in a prestigious department. Although possession of a doctorate reduces specialist training by only a year, serious research is usually needed to get even some non-university jobs.

Teaching and research remain areas where working hours are not defined and the status of academics is high, with professors earning more than ordinary heads of departments (they get both a head of department's salary and a professor's salary). Apart from fears that the older students will have less time and inclination to do research Swedish academics are also concerned about the inroads made into their time by the increasing pressures of clinical work, especially as there are few pure clinical research posts available.

\section{Into the '80s}

Sweden's health service is an expensive one-visibly so in its modern and well-equipped hospitals and health centres-and it is likely to become more so. Spending on health already approaches $10 \%$ of GNP (it is $5.6 \%$ in the UK), and plans for the ' 80 s recognise that the service will need increased revenue that will not necessarily improve provision because it will go on higher wages and shorter working hours. On top of that extra funds are needed to cope with demands created by the high proportion of elderly people. The problem for the planners is how to reconcile this increased expenditure with a reduced economic growth rate and a smaller working population to bear the tax burden. 


\section{Review Body award}

\section{Implementation in Scotland}

Hospital and community medicine doctors in Scotland may not receive their increased pay award in their June pay cheques. The draft implementation circular was cleared on 3 June by the chairman of the SCHMS and SCCM and the substantive circular was issued on the same day. The BMA Scottish Office has learnt subsequently that for those boards dependent on the Tayside computer for staff payments the "cut-off" date had been advanced to the fourth of the month. The SHHD has been asked to arrange manual payment by health boards as soon as possible in July if the increases are not paid through the computer by 30 June.

\section{GMS Committee (continued from page 1639)}

recorded in Hansard on 26 May 1978 as being accepted by the Minister of State:

'Identifiable information is to be regarded as held for the specific purpose of the continuing care of the patient and should not be used without appropriate authorisation or the consent of the patient (parent or guardian in the case of a child) for any other purpose.

'Access to identifiable information held in medical records is to be confined to the author and to the person clinically responsible for the patient during the episode from which the data has been collected (or their successors) unless specifically authorised by the clinician in the clinical interest of the patient.

'An individual is not to be identifiable from data supplied for statistical or research purposes except when follow-up of the individual patient is a necessary part of the research (and either the patient has given informed prior consent or consent has been obtained from the chairman of an appropriate ethical committee).'

The committee has fully endorsed the report of its Confidentiality Safeguards Working Party which specified procedures for the secure operation of the system.

Four other vital resolutions have been unanimously supported:

'This committee recommends the Department to accept the Child Health Computing Committee's Confidentiality and Safeguards Report and commend it as a code of practice for implementation by Authorities operating any part of the standard child health system.'

'This committee would recommend appropriate sanctions, to the extent of dismissal, in any case of a breach of confidentiality. The committee recognises the urgent need for the development of a code of practice to protect the confidentiality of personal medical records.'

'This committee commends the recommendations in the Child Health Computing Committee's Confidentiality Safeguards Re-

\section{New fees for Government work}

Following negotiations by the BMA the fees for part-time work undertaken on behalf of Government departments have been increased by $31 \%$ with effect from 1 April 1980 or as soon as possible thereafter in the case of statutory fees.

\section{General practitioners}

Chairman of medical board: $£ 29.60$ (session); $£ 11.80$ (single case).

Member of medical board: $£ 23.50$ (session); $£ 8.65$ (single case).

Full medical examination and report: $£ 13$

Examination of $\mathrm{HGV}$ drivers: $£ 13$

Extract from a GP's records: $£ 3 \cdot 85$ to $£ 5 \cdot 30$.

Medical supervision of establishments:

Up to one hour: $£ 8.65$ (day); $£ 17.35$ (night).

One to two hours: $£ 15 \cdot 90$ (day); $£ 31 \cdot 10$ (night).

Two to three hours: $£ 23.50$ (day); $£ 41.60$ (night).

\section{Consultants}

Medical appeal tribunals: $£ 72$ for day or part of day

Appeal boards: one case $£ 36$.

Medical boards or specialist treatment:

One case: $£ 23 \cdot 50$.

Two cases: $£ 29 \cdot 60$.

Session: $£ 36$.

Examination and advice on individual cases : $£ 23.50$ to $£ 34$.

\section{Postmortem examinations and attendance at inquests}

Special examination and report: $£ 73$.

Special examination, report, and giving evidence at inquest: $£ 88$

Examination and reporting result to coroner: $£ 26 \cdot 05$.

Examination, reporting result to coroner, and giving evidence at inquest: $£ 41 \cdot 60$.

\section{Fees for witnesses to fact called by the Crown}

Under four hours: $£ 20 \cdot 80$.

Over four hours: $£ 41 \cdot 60$.

Negotiations are taking place for increases to the fees payable to doctors helping local authorities, for sessional work in the community health services, and life assurance report fees.

For copies of the new Government department fees BMA members should apply to the BMA Secretary, BMA House, Tavistock Square, London WC1H 9JP. A stamped addressed envelope (6 in 9 in) would be appreciated. Queries relating to individual fees should be made to members' regional offices.

port to the Department as a basis for appropriate legislation.'

'The Child Health Computing Committee recommends that the British Medical Association be given observer status in the trial areas of the preschool system.'

The committee believes that there is now no remaining ethical issue which would rightly prevent the preschool system trials taking place.
On the question of computer technology the committee has the expert advice of the Welsh Health Technical Services Organisation.

The system designed will be capable of being updated as technology becomes available within the NHS."

Dr Alan Rowe, deputy chairman of the CEC, agreed to discuss the CHCC's resolution matter with his committee and there will be a report at the next GMSC meeting. 